\title{
Nursing Education During COVID-19 Pandemic: Way Forward for Teaching Hospitals in Nepal
}

Babita Sing $^{1 *}$, Rakesh Sing ${ }^{2}$

Author Info:

${ }^{1}$ National Medical College Teaching Hospital, Birgunj, Parsa, Nepal

${ }^{2}$ Patan Academy of Health Sciences, Lalitpur, Nepal

\section{Corresponding Author:}

Ms. Babita Singh

Email/Contact:

bobysin7181@gmail.com

$+977-9842060090$

\section{ABSTRACT}

COVID-19 pandemic has affected nursing education globally, with more impact in nations like Nepal with limited resources. Although, the use of technology and virtual platforms has long history in nursing education, it is relatively very new for teaching hospitals in Nepal where the health system is fragile. The challenges seen in nursing education have depicted an urgent need to address nation's gaps in educational infrastructure including capacity building of faculties and enabling nursing students to utilize technology effectively. In fact, the pandemic has unveiled underlying structural vulnerabilities and existing disparities in educational settings between nations, particularly in nursing education.

Keywords: COVID-19, Nepal, nursing education, pandemic, teaching hospitals
Quick Response (QR) Code

Scan Me for Full Text

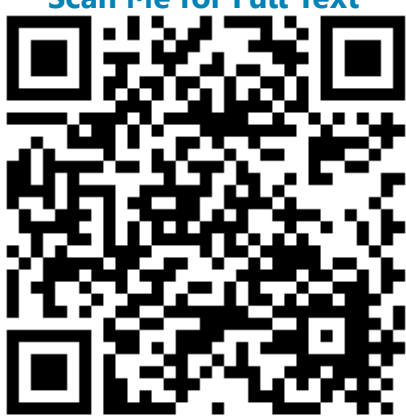

View PDF

\section{Article Info}

Received: 1 August 2020; Accepted: 19 September 2020; Published Online: 20 September 2020 How to cite this article in Vancouver Style?

Singh B, Singh R. Nursing Education during COVID-19 Pandemic: Way Forward for Teaching Hospitals in Nepal. Europasian J Med Sci. 2020; 2(2):24-27. https://doi.org/10.46405/ejms.v2i2.126

\section{Disclaimer}

Conflict of Interest: None Declared;

Source of Support: Nil

Copyright: $(2020$ by author(s). This is an open access article distributed under the terms of the Creative Commons Attribution International License 4.0 (http://creativecommons.org/licenses/ by/4.0/) which permits unrestricted use, distribution, and reproduction in any medium, provided the original work is properly cited.

\section{Publisher's Note}

The Europasian Journal of Medical Sciences (EJMS) (www.europasianjournals.org) is an official Journal of Nirvana Psychosocial Care Center \& Ressearch Institute (www.nirvanapscc.com). The Journal as well as publisher remain neutral with regards to any jurisdictional claims in any published articles, its contents and the institutional affiliations of the authors. 


\section{INTRODUCTION}

The novel nature of agent severe acute respiratory syndrome coronavirus-2 (SARS-CoV-2), its mode of transmission, and its consequences have led to fears, worries, and anxiety among individuals worldwide. The outbreak was first identified in Wuhan, Hubei, China, in December 2019. The World Health Organization (WHO) declared the outbreak of coronavirus disease (COVID-19) as a Public Health Emergency of International Concern on $30^{\text {th }}$ January, 20201. The number of infected individuals and deaths from COVID-19 is increasing daily worldwide. Despite probably the highest social and public health measures history to contain and prevent spread of the disease, COVID-19 has reached and impacted in 213 countries and territories and two international conveyances as of $15^{\text {th }}$ July, 2020 according to Worldometer COVID-19 data. Similarly, Nepal ranked $24^{\text {th }}$ in term of reported cases of COVID-19 amongst 49 affected Asian countries, according to worldometer COVID - 19 data.

The direct and obvious impact of the pandemic is seen on health and economy, but it has not spared any sector. ${ }^{2}$ Education in Nepal has experienced a major challenge as a consequence of COVID-19 pandemic and nation-wide lockdown. Schools and colleges are closed, students are relocated to their homes and hostels were emptied before the beginning of lockdown. As COVID-19 pandemic is becoming widespread, its consequence on nursing education is becoming more extensive globally. ${ }^{3}$ In line with the Nepal government's call to help flatten COVID-19 curve, the Nursing Campus at National Medical College Teaching Hospital (NMCTH) in Nepal decided to suspend all face-to-face (F2F) routine didactic lecture classes, clinical placements in different wards, Out Patient Departments, community postings and continuous assessment like Unit tests, internal assessments and clinical evaluation since $22^{\text {nd }}$ March 2020.

\section{CHALLENGES IN NURSING EDUCATION}

On one hand, the suspension of academic activities along with COVID-19 control measures including social distancing and travel restrictions create a risk to loneliness and psychological problems among students ${ }^{4}$. On the other hand, uncertainty about their clinical education and future due to the pandemic would not only lead to a considerable loss of learning time for nursing students, it would also lower their self-esteem, confidence and loss of clinical skills ${ }^{5}$. Under such context, finding an appropriate strategy to minimize such losses, to ensure the safety of students, brought up the need to find other approaches to minimize the impact of lockdown on academics ${ }^{6}$ and reduce the risk of stressors in nursing students. This led to making use of a readily available virtual platform, considered as a novel approach to continue delivering nursing education during this pandemic ${ }^{3}$ which became the only viable solution for Nursing Campus, NMCTH. While measures of physical distancing are in action, we resumed the nursing educational activities including lectures and few clinical presentations like reports of clinical teachings majorly via online platform (Zoom) since $23^{\text {rd }}$ April 2020. Although, online education has been a concept carrying long history, the shift towards delivering nursing education curricula using technology via online platforms is relatively a new pedagogic method for nursing schools and teaching hospitals in Nepal. The resumption of educational activities via virtual platforms chiefly covering the cognitive domain (theoretical portion) of the curriculum has helped both faculties and students at Nursing Campus, $\mathrm{NMCTH}$. However, formative and summative assessments for core knowledge are yet to be started by using a variety of online tools and platforms.

NMCTH, a private institution affiliated to Tribhuwan University, set up in 2001, is dedicated to the sustained improvement of health of people in Nepal through innovation in higher education in health sector. The current shift towards early resumption of medical and nursing education is an example of its commitment towards students and society. However, it's well known there are two sides of an innovation. On one side, resumption of theoretical sessions alone though will not completely compensate the impact of COVID-19 on nursing education; it will certainly help to reduce such impact by covering at least a portion of nursing curriculum, reducing the loss of study duration for students, and actively engaging both faculties and students in academic activities. On the other side, quick shift to online platforms is disrupting curriculum implementation as the theoretical and practical portions of most of the nursing subjects need to be demonstrated in the skill lab, before placing the students in the clinical areas, which is not possible to implement through online classes. Also, the cost of running an online class is high both to institutions and students and not all students will be able to access online lessons due to lack of internet connectivity in some remote areas. 
Moreover, the online teaching mode is new to many faculties for delivering educational contents at nursing campuses and teaching hospitals in Nepal. Also, the effectiveness of such online pedagogy depends on students' and faculties' readiness, knowledge, attitude and skills to use technology and online platform. Hence, it is required to assess the effectiveness of delivering contents of nursing education program through online platforms in developing countries like Nepal. Additionally, capacity building of faculties towards using virtual platforms to deliver educational contents has been a need of the hour for nursing campuses and teaching hospitals in

The fact that the nursing education is moving online may have created disappointment amongst some of the students, especially those in clinical clerkships where they apply theoretical learning into practice and acquire clinical skills and acumens chiefly belonging to psychomotor and affective domains through concurrent exposure and interactions with patients. However, there is no alternative than to suspend clinical clerkships at present context in low-income countries due to the safety concerns. The shortage of personal protective equipment is one of the major factors for students' non-engagement in clinical settings and their safety being at the forefront of teaching hospital's policy at the moment.

\section{RECOMMENDATIONS}

The corona outbreak created a world of ambiguity, loss of control and uncertainty. The feeling of losing control is very stressful for the general population and especially for students. The faculty has an important role to create a sense of control and provide the stable educational structure for the students. Despite online education being a novel approach brought into nursing education in Nepal, it is believed that nothing can replace the clinical placements that help foster decisionmaking skills, empathy and professionalism in students by integrating learning on skills of history-taking, physical examination and clinical reasoning ${ }^{7}$. While two-third of the surveyed medical students preferred to immediately return hospital setting to continue their education in Singapore, the remaining showed hesitancy with reasons including not wanting to drain physician's time during pandemic and not considering selftrained to stay safe ${ }^{8}$. However, as the context differs between nations, the perception among nursing students may also vary due to differences in resources, grooming and skills. It may be a topic of debate on whether to bring back nursing students to hospital setting or not, particularly in developing nations like Nepal where healthcare system is fragile and is not well prepared to fight the outbreaks ${ }^{9}$. In this regard, assessing nursing students' preference towards returning hospital setting during pandemic is a need of nursing education research in developing nations. As the analysis of knowledge of the preference of students themselves regarding resumption of their clinical education on an individual level, may provide useful insight into a student's resilience, burnout, tolerance for uncertain situations, sense of professional identity, motivation for learning, and awareness and assessment of disease risk. From nursing school perspective, this may reflect a shortcoming of an educational program to appropriately support students in these areas.

As the continuous assessment and timely feedback are key features of nursing education, it cannot be suspended for a long time. The successful implementation of the first ever online examination for final year medical students at Imperial College of London ${ }^{10}$, is a lesson learnt for many medical and nursing schools globally to think of alternative methods of examinations in medical and nursing education. It is again a topic of interest and need a critical thinking and an assessment regarding feasibility of online examination of nursing students in limited resource settings like in Nepal where faculty- and staff in nursing schools and teaching hospitals are new to such alternative method.

Nursing students are already disconnected from their routine face to face education system and for preparing a skillful and professional nurse it is must to relate the theory with skill labs and then hands on practice is required to teach nursing skill. Right now, we are emphasizing on online education, so its recommended that expertise of skills will be required for online simulation programs and digital labs. For this initiative must be taken by the concerned universities and related councils to train the proper and adequate nursing professionals.

\section{CONCLUSION}

Under the disruption of this pandemic, it is uncertain what the future of nursing education is going to look like especially in developing nations like Nepal. Nevertheless, it's also creating opportunities to brainstorm about alternatives of learning techniques such as virtual education and tele-technology. Moreover, capacity building of 
faculty and staff members in delivering educational contents and assessing the students through online platforms have been evolved as the current need of nursing education. Whatsoever be the future like, it would be better to integrate information technology so that online teaching-learning will eventually become an integral part of nursing education and the whole health sector can benefit in overcoming future challenges in the events of ongoing as well as forthcoming disaster, epidemic and pandemic.

\section{REFERENCES}

1. World Health Organization. (2020) 'Statement on the second meeting of the International Health Regulations (2005) Emergency Committee regarding the outbreak of novel coronavirus (2019-nCoV)', Geneva (Switzerland), WHO. Accessed: 23 May 2020. [Link]

2. Nicola M, Alsafi Z, Sohrabi C, Kerwan, A. et al. (2020) 'The socio-economic implications of the coronavirus pandemic (COVID-19): A review', Int J Surg, 78, pp. 185-193. https://doi.org/10.1016/j.ijsu.2020.04.018. [Google Scholar] [PubMed]

3. Sandhu P, de Wolf, M. (2020) 'The impact of COVID-19 on the undergraduate medical curriculum', Medical Education Online, 25, 1764740. https://doi.org/10 $.1080 / 10872981.2020 .1764740$. [Google Scholar] [PubMed]
4. Singh R, Baral KP, Mahato S. (2020) 'An urgent call for measures to fight against increasing suicides during COVID-19 pandemic in Nepal', Asian J Psychiatr, 54, 102259. https://doi.org/10.1016/j.ajp.2020.102259. [Google Scholar] [PubMed]

5. Mian A, Khan S. (2020) 'Medical education during pandemics: a UK perspective', BMC medicine, 18(1), 100. https://doi.org/10.1186/s12916-020-01577-y. [Google Scholar] [PubMed]

6. Abbasi S, Ayoob T, Malik A, Memon SI. Perceptions of students regarding E- learning during Covid-19 at a private medical college. Pak J Med Sci. 2020;36 (COVID19-S4):COVID19-S57-S61. https://doi. org/10.12669/pjms.36.COVID19-S4.2766. [Google Scholar] [PubMed]

7. Spencer J. (2003) 'Learning and teaching in the clinical environment', BMJ, 326(7389), pp. 591-4. https://doi.org/10.1136/bmj.326.7389.591. [Google Scholar] [PubMed]

8. Compton S, Sarraf-Yazdi S, Rustandy F, Kumar R.KL. (2020) 'Medical Students' Preference for Returning to the Clinical Setting During the COVID-19 Pandemic', Medical Education. https://doi.org/10.1111/ medu.14268. [Google Scholar] [PubMed]

9. Poudel A. (2020) Dengue outbreak exposes the country's fragile health care system, The Kathmandu Post, Nepal . Accessed: 25 June 2020. [Link]

10. Tapper J, Batty D, Savage M. (2020) Medical students take final exams online for first time, despite student concern, The Guardian. . Accessed: 22 March 2020. [Link] 